\footnotetext{
Community engagement in Aotearoa New Zealand is a variable practice. Generally driven by local and central government, much of it could be described as superficial at worst and naïve at best. This paper sets out concerns with existing practice as evidenced by my own experiences working on projects with local and central government. Drawing heavily on Atawhai Tibble's tips for engaging with Māori, I outline how we might move engagement towards meaningful practice that is rooted in the Aotearoa New Zealand context.
} 


\section{Engaging Communities in the Design of Homes and Neighbourhoods in Aotearoa New Zealand}

\section{REBECCA KIDDLE}

Cities have the capability of providing something for everybody, only because, and only when, they are created by everybody. Jane Jacobs ${ }^{1}$

It seems cliched to talk about community-engagement processes with respect to housing provision in Aotearoa New Zealand given the breadth of work, writing, and frameworks that have been developed across the globe on how to do this well. ${ }^{2}$ There are a number of related terms and concepts often used to mean the same or similar, including participatory design or planning, community design or planning, democratic design, and co-design. In this paper, the overarching term 'community engagement' is generally used, though these other concepts are drawn on where authors have used them to elucidate some aspect of community engagement. There are also multiple definitions of community engagement. The most widely accepted definitions focus on it as a process whereby the public can be involved in decision-making, even if the actual or desired

1 Jane Jacobs, The Death and Life of Great American Cities (New York: Modern Library, 1993), 238.

2 Ngā mihi to Hirini Matunga, Isabella Cawthron, and the anonymous reviewer for their useful and thoughtful comments on the first draft of this paper. 
level of, and rationale for, that involvement varies widely. ${ }^{3}$ Finally, there are a range of reasons why it is important. These include a growing body of evidence that shows engagement can support improved outcomes, ${ }^{4}$ that it is damaging to the community to not have opportunities to participate as citizens in a democratic process, ${ }^{5}$ and that it is a human right. ${ }^{6}$

Despite a seemingly widespread acceptance that it is important, we still fail to do engagement systematically well in this country. Central and local government officers, developers, and designers appear to say the right things, but after the dust has settled and the heat pumps are installed, have those who were employed to consult or engage with communities really achieved the level of engagement needed to add sustained value to those who will inhabit these houses and make them homes?

Even award-winning engagement processes have, according to alternative accounts, been found wanting. Take, for example, the Tāmaki regeneration project in Auckland, which in June last year won an Australasian Housing Institute award for its engagement efforts. This project saw social housing tenants abruptly displaced, with many given only 90 days to leave their homes-homes in which some had lived for up to 50 years prior, a length of stay based on a previous policy that had offered a state house

3 Sally Hussey, 'Why is Community Engagement Important?' Bang the Table, n.d; Australian Institute of Family Studies, 'Community Engagement: A Key Strategy for Improving Outcomes for Australian Families,' CFCA paper no. 39, Australian Institute of Family Studies, 2016.

4 David Yeboah, 'A Framework for Place Based Health Planning,' Australian Health Review 29, no. 1 (2005): 30-36; AIFS, 'Community Engagement'; Hussey, 'Why is Community Engagement Important?’

5 Amartya Sen, 'Human Rights and Capabilities,' Journal of Human Development 6, no. 2 (2005): 151-166; Michael Marmot, Status Syndrome: How Your Social Standing Directly Affects Your Health and Life Expectancy (London: Bloomsbury, 2004); Kate Pickett and Richard Wilkinson, The Spirit Level: Why More Equal Societies Almost Always Do Better (London: Allen Lane, 2009).

6 Usman Khan (ed.), Participation Beyond the Ballot Box: European Case Studies in State-Citizen Political Dialogue (London: Routledge, 1999); Vivien Lowndes, Lawrence Pratchett, and Gerry Stoker, 'Diagnosing and Remedying the Failings of Official Participation Schemes: The CLEAR Framework,' Social Policy and Society 5 , no. 2 (2006): 281-291. 
'for life'. ' As Renee Gordon writes of the government agency tasked with engaging communities in this project, it was 'consultation-heavy and light on action', despite the agency having worked in the area for a number of years prior to the eviction notices being sent out. ${ }^{8}$

With increasing pressure on Aotearoa New Zealand's housing stock, central government has recently invested, or pledged to invest through programmes such as Kiwibuild or Kāinga Ora's large-scale urban-regeneration programme, a considerable amount of money in the redevelopment of neighbourhoods characterised by large tracts of state housing close to urban centres (for example, Tāmaki and Eastern Porirua). ${ }^{9}$ In addition, local councils across the country, as part of their long-term and short-term strategic-planning processes, are mandated to consult with their communities on future development paths. ${ }^{10}$ Many are engaged in either developing their own affordable housing or are being encouraged by Local Government New Zealand (LGNZ) to 'stimulate the supply of affordable housing within their communities'. ${ }^{11}$ Engaging communities will be important if these projects are to be successful in the long term.

This paper provides a reflective account of some of my experiences undertaking community engagement in a range of communities. I am Ngāti Porou and Ngā Puhi and my training is in urban design. I am currently a senior lecturer in urbanism at the Wellington School of Architecture, Te Herenga Waka Victoria University of Wellington, and my work addresses issues of spatial and decolonial justice. I have worked in both the United Kingdom and Aotearoa New Zealand on projects that are rooted in meaningful engagements with 'hard to reach' communities,

7 Renee Gordon, State-led Gentrification and Impacts on Residents and Community in Glenn Innes, Auckland (Masters thesis, University of Auckland, 2015), 120.

8 Gordon, State-led Gentrification, 120.

9 See: https://www.tamakiregeneration.co.nz/. See also, Taankink and Robinson,

'Dispossession and Gentrification in the Porirua Redevelopment,' this issue.

10 Many councils are undertaking redevelopment projects. An example is Wellington City Council: https://wellington.govt.nz/your-council/projects 11 Local Government New Zealand, 'Housing 2030: Affordable Housing,' n.d., https:/www.lgnz.co.nz/housing2030/supply/affordable-housing/ 
including rangatahi, Māori, and Pasifika communities. All of these projects have taken as necessary the need for an educative and capacity-building element to the engagement process, ensuring that communities and external designers alike have the tools to respond in a way that directly links their lived experiences with built-environment best practice.

To explore some of the issues with community engagement, this paper discusses projects led by both local and central government that aimed to include the voices of the community in setting the direction of housing and urban development. All of the projects are ongoing; I have chosen not to explicitly identify them because of this. However, I do draw on specific examples from these experiences to exemplify and generalise what needs further deliberation if we are to achieve systematic change around how engagement is done in this country.

To give some general context, all of the communities I have worked in have large (sometimes majority) Māori and Pasifika populations and large rangatahi populations. They have also tended to be lower-socio-economic communities.

The paper begins by highlighting concerns with how engagement by local and central government and built-environment professionals is done in Aotearoa New Zealand. It then suggests what a more meaningful engagement process might look like, drawing heavily on Atawhai Tibble's 'engaging with Māori tips'. ${ }^{12}$ These tips come from Tibble's experiences of being on marae for 50 years. While he focuses on engaging with Māori, his thoughts are applicable when approaching other communities too.

\section{Existing public-participation practice in Aotearoa New Zealand}

In Aotearoa New Zealand, local and central government entities and builtenvironment specialists draw on IAP2, a model for public participation. ${ }^{13}$

12 Atawhai Tibble, 'Engaging with Māori - it's about the Who, the What's, Why's and How to's?' Linkedin, 21 June 2019.

13 See: https://iap2.org.au/ 
IAP2 is a 'public participation spectrum' that identifies a range of levels of participation possible when decisions need to be made that affect the public. The differing levels of engagement are used to signal to communities how much engagement and decision-making might be expected at different points in the process, depending on the 'goals, time frames, resources and levels of concern in the decision to be made. ${ }^{14}$ At one end of the spectrum, the goal is merely to 'inform' the public; at the other end, it is to 'empower'. ${ }^{15}$

The IAP2 is a generalised engagement tool for use in a range of national and cultural contexts, and as such has been hugely influential worldwide. As yet, there have been no comprehensive efforts to involve Māori in these engagement processes, nor to think through how te Tiriti obligations might be met when using this generalised tool. ${ }^{16}$

There have been some positive recent advances of engagement with iwi as 'partners' in development processes, an example being Porirua Development's partnering with Ngāti Toa Rangatira. ${ }^{17}$ However, this alone is not enough. Work is needed at all administrative levels to ensure that mana whenua are truly partnered with, particularly when iwi are relatively small entities who often have little resource and capacity to engage extensively in these projects, let alone respond to all the other projects across a range of sectors that they are called to be involved in. Non-responses by iwi to engage are often interpreted as disinterest, when in reality many iwi face competing demands. ${ }^{18}$ Requests for engagement are also rarely

14 International Association for Public Participation, https://iap2.org.au/

15 International Association for Public Participation, 'IAP2 Spectrum of Public Participation', 2018, https://iap2.org.au/wp-content/uploads/2020/01/2018_IAP2_ Spectrum.pdf

16 Te Tiriti o Waitangi is used here to suggest that the obligations and conditions set out in the te reo Māori version of the Treaty of Waitangi are the ones Aotearoa New Zealand should adhere to.

17 See: https://poriruadevelopment.co.nz/. See also, Taankink and Robinson, 'Dispossession and Gentrification in the Porirua Redevelopment,' this issue.

18 Peter Horsley, 'Collaborative Management: Pre-conditions and Prospects, Murihiku Marae, 25-27 August, 2000. 
accompanied by the resources needed to empower iwi to engage.

Adding further complexity here are the many Màori who are not mana whenua who live in these communities (who are sometimes called mātāwaka or urban Māori). This group often falls through the cracks in government-led engagement processes, with government assuming it has done its job engaging Māori communities once mana whenua engagement has taken place. ${ }^{19}$

The IAP2 spectrum is simply an instrument to communicate the level of engagement. If used in isolation of the training programmes that sit behind IAP2, it is not enough to ensure successful engagement outcomes in Aotearoa New Zealand's cultural, social, and economic context, let alone in relation to Māori communities. From my experience in housing and urban design projects, government officials skew toward the light-engagement (inform and consult) end of the IAP2 spectrum. Public-participation theory and best practice would suggest, however, that involving, collaborating, and empowering communities (the heavy-engagement end of the IAP2 spectrum) is critical to the success of longer-term housing outcomes. ${ }^{20}$

Government authorities' decisions concerning the level of engagement are influenced by democratic obligations, the ability to unilaterally make decisions (that is, the level of authority they possess), the underlying ethos of the organisation with respect to engagement, and the government's social licence to operate within any given community. Generally, government agencies appear apprehensive of in-depth engagement processes. FrançoisPierre Gauvin and Julia Abelson give four possible reasons for this: (1) government officials might be sceptical about how much value engaging the public might generate; (2) officials might fear that the community

19 Hauauru Rae and Michelle Thompson-Fawcett, 'Kia Tahuri i te Riu, Kia Tika: Indigenous Participation in Earthquake Recovery Planning - Insights from Taiwan and Canterbury,' in Our Voices: Indigeneity and Architecture, eds. Rebecca Kiddle et al (San Francisco: ORO Editions, 2018).

20 See, for example, Beth Milton et al, 'The Impact of Community Engagement on Health and Social Outcomes: A Systematic Review,' Community Development Journal 47, no. 3 (2012): 316-334. In this systematic review of literature on community engagement in the UK, it was found that community engagement had positive impacts on housing, crime, social capital, and community empowerment. 
will hijack the process and undermine their authority, and relatedly that expectations might rise to a point that cannot be managed; (3) officials managing limited resources and working to tight deadlines might be unwilling, or feel unable, to invest in engagement; and (4) there may be assumptions that elected officials either already represent public opinion or, if engaging widely, are relying on it too much and are not exercising leadership. ${ }^{21}$ With the stresses of government priorities and the pressure to deliver housing quickly, as evident in Phil Twyford recently losing the housing portfolio, engagements can easily fall closer to the 'inform' end of the spectrum and become superficial and tokenistic.

Decisions around when to involve communities also tend to fall wholly to those leading the development. An example of the importance of timing and involving the community early on includes a project I was recently involved with where the proposed development had been announced a few months earlier and the engagement process had not yet commenced, but a worried group of community members rallied together and organised themselves to critique the government's plans for the development. ${ }^{22}$ The community had heard little since the announcement of the original project and wanted more transparency about what was happening. They were very critical of the government agency that was leading the project due to feeling left out of the process. The agency immediately worked to 'defend' itself. The agency rejected my suggestion that it involve a key member of the community group-who could have provided a critical eye on the engagement and development plans as they were progressing-by saying, 'but they are critical of us'. Surely, the role of government as a vehicle for democracy is to engage with both critical and supportive voices?

Proactive and vocal local groups that clearly represent at least some of the community, as in the example above, deserve a space in which their voices are heard and acted upon, particularly given the importance

21 François-Pierre Gauvin and Julia Abelson, 'Primer on Public Involvement,' Health Council of Canada, 2006, 12-13.

22 As this is an ongoing project, I will not prejudice the process by giving any specific information about it. I include it here because it is typical of what I have experienced when working in this area. 
and longevity of housing projects. Having community members who are directly affected-who are critical and engaged enough to rally together and form a political action group-is a fabulous asset to the development process, ensuring that decisions are robust and well thought through. Of course, care needs to be taken to involve a range of community members who represent different areas of concern and interest in the neighbourhood. Investing in relationship building at the start of such processes helps to mitigate capture by any one group. Government targets and development pressures (for example, that we need to produce $x$ number of houses by $y$ date) — which come with their attendant political or financial strainsoften result in insufficient, or a total lack of, early work around relationship building.

The communities affected by the projects I have worked on in Aotearoa New Zealand have all had to fight hard for representation on the governance boards that oversee development processes. In addition, in these projects, high-level principles around how the development process will proceed and how government will work with communities have not been developed early on, resulting in communities feeling 'on the back foot' right from the start.

If relationships are built, the actual engagement often ends up being done in a way that presumes that you just ask communities what they want, the designers take that away, and voila, a couple of designs are produced and the community votes on which one they like best. This neglects the fact that design should be a reciprocal process grounded in democracy and oriented towards collective benefit. Bobby Nisha and Margaret Nelson suggest there is a tension between what they call a 'subjective product focused approach' and a 'process-oriented approach'. ${ }^{23}$ They assert:

The product-based subjective approach has been criticised for focusing on the needs of either the developer or the designer, with little regard for the needs of the users. As a result, consultation exercises undertaken are viewed

23 Bobby Nisha and Margaret Nelson, 'Making a Case for Evidence-Informed Decision Making for Participatory Urban Design,' Urban Design International 17, no. 4 (2012): 336-348. 
as tokenistic or simply paying lip service to the idea of a participatory urban design process. ${ }^{24}$

Alongside this, in most cases, those who undertake the engagement are in separate teams or entities from those responsible for the design. Further, the interconnection between community-engagement officers and the design team varies, and in my experience loose connections are detrimental to the design outcomes. The engagement process in such situations tends to involve the following five steps: (1) communities are asked blue-sky questions like 'what do you like and what don't you like about your neighbourhood?' and this information is then given to designers; (2) designers produce some concept designs; (3) the community is then presented a few design options; (4) the community says which one they like best and will point out any weaknesses, with their engagement with the process ending here; (5) the design is revised on the basis of the information provided by the community and construction commences. While this process includes some important first steps, a more in-depth engagement process is needed. Much can happen between the initial engagement and construction, and if communities are not kept in the loop, they might be disappointed by the final design proposal if they are unable to easily see the connections between the outcome and their earlier feedback.

To use urban-design speak, the urban-design element of a regeneration or development project is both a process and the design product. As Jay Doblin argues, the traditional design approaches that focus on product design are no longer effective: 'For years, most design problems could be solved by using a combination of design training, experience, and applied intuition; but as the world and its design problems have become more complex, traditional approaches have become less effective'. ${ }^{25}$

There is a further problem in these participation processes: the community members who are engaged with to imagine new possibilities generally do this for free. They provide a wealth of mātauranga as users

24 Nisha and Nelson, 'Making a Case for Evidence-Informed Decision Making,' 345.

25 Jay Doblin, 'A Short, Grandiose Theory of Design,' STA Design Journal (1987): 6-16. 
and residents of existing neighbourhoods, and they offer nuanced understandings of the social and cultural life of an area, including how these might be impacted upon—-negatively or positively—by physical changes to the space. Engagers and designers, on the other hand, tend to be paid well for undertaking their roles. Notwithstanding altruistic motivations for being involved, the paid professionals will happily bask in any accolades awarded for the finished product, yet the submissions made for architectural or engagement prizes seldom include thanks to the residents for the "heavy lifting' involved in providing inspiration and rationale for design proposals.

There also seems to be a penchant for prioritising international examples and precedent, with some believing they are superior to the culturally rooted examples of best practice found here in Aotearoa New Zealand. Relatedly, the common presupposition that external (to the community) engagement and design consultants are objective, value-free beings that can do a better job because of their 'detached' viewpoints, belies the fact that we all hold biases and values that dictate how we work and the decisions we make. As Jon Lang asserts, urban design is an 'ongoing highly valueladen argumentative process'. ${ }^{26}$ Disregarding or failing to understand this can lead to naïvely sourcing seemingly 'objective' managers and consultants from outside the community without looking to local expertise first.

If international evidence continues to be more compelling, then perhaps Marc Parés et al's article from Urban Studies, one of the highest ranking urban-focussed journals, might convince government strategists and decision-makers. As the researchers argue:

regeneration processes that aim to address the problems of disadvantaged urban areas in a holistic manner and through intense participative processes are much better equipped to politically empower the poor and to counteract socio-spatial inequalities than technocratic and physically oriented regeneration processes. ${ }^{27}$

26 Jon Lang, Urban Design: The American Experience (New York: Van Nostrand Reinhold, 1994).

27 Marc Parés, Marc Martí-Costa, and Ismael Blanco, 'Geographies of Governance: How Place Matters in Urban Regeneration Policies,' Urban Studies 51, no. 15 (2014): 3265. 
Sungnam Park, on the basis of their work in the UK, suggests that urban design should play 'a role as "a place-shaping mechanism" . . . and it should respond to the questions of "place shaping for whom?"; and "whose place in relation to existing local communities?"'. ${ }^{28}$ The next section further explores the role of community engagement in urban-design processes, and seeks out more meaningful ways to engage communities, ways that are grounded in the Aotearoa New Zealand context.

\section{Progressing towards more meaningful community engagement}

The ubiquitously used IAP2 spectrum, while useful for clarifying engagement levels, fails to offer a culturally and nationally specific response that acknowledges te Tiriti. Tibble offers a considered and pragmatic set of tools for engaging with Māori communities specifically, but as mentioned above, his suggestions are also relevant for engaging with the wider community in genuine and meaningful ways. At the centre of Tibble's approach to engagement is the importance of building relationships and personal rapport with communities.

First, he suggests that building rapport might require a 'thousand cups of tea', emphasising the importance of building real relationships when undertaking engagement: 'Real relationships with Māori take real "face" time, over time. This is not Tinder!'. ${ }^{29}$ He points out that these are, indeed, personal relationships sealed with a 'hongi and/or kiss, cos we don't just shake hands'. This, he suggests, is because 'generally, we go personal, and communal, before transactional'.

Timing matters, and the pre-work required to build rapport with communities and Tiriti partners is time consuming. It involves identifying all of the different players, both vocal and not so vocal, and those who

28 Sungnam Park, 'The Social Dimension of Urban Design as a Means of Engendering Community Engagement in Urban Regeneration,' Urban Design International 19, no. 3 (2013): 184.

29 All quotes below are from Tibble, 'Engaging with Māori.' 
are positive about new housing and urban redevelopment and those who are not. 'Hard to reach' groups might be suspicious of outsiders or may feel generally alienated from official processes. Many also have other things going on for them that make engaging in neighbourhooddevelopment consultation a low-level priority. Careful thinking is required around how best to get everyone, or at least many people, to the table. Working with community leaders around where, when, and with whom to consult is crucial work that needs to be done right at the beginning. Key representatives also need to be included in the governance groups that oversee housing and urban-development projects.

Second, Tibble asserts the need to observe appropriate tikanga when meeting with Māori, but this would hold true for a range of cultural groups. He suggests karakia are important here. Karakia is often translated to mean prayer, which may be off-putting for some, but he suggests 'Māori mindfulness' as an alternative translation, denoting a desire to be 'mindful of what we are doing, why, for who'. This moment at the start and end of meetings offers space to pause, 'reflect on purpose, on the people and the "mana” present, we are optimistic, and we show gratitude!'.

Relatedly, Tibble holds that the ritual of mihimihi is an important precursor to relationship building: 'Always Mihi, before the Mahi. (Continuing on, in our encounter rituals we present our full selves, not just our work titles. We share to connect. And, we do this before we dive into work.)'. Engagement starts with listening and watching, not speaking. Understanding who you are talking with, and what concerns or goals they may have for urban-development projects, should come before we speak ourselves and ask those assembled what we want of them. 'Whakarongo, titiro ... kōrero. (Listen, watch . . . then speak. Soak up what's going on. Be alert. Be curious. You won't regret it.)'.

Finally, Tibble suggests that engagers need to be prepared to be present until the end. He advocates for never taking the first flight back. Instead, 'take the last one, or the first one the next a.m. (Be present. Not on your cell phone, or at another hui. Be there and stay till the end. Don't be that “official” who has to leave before proper farewells!)'. 
Engagement needs to be built on what Tibble calls 'tea-towel-tanga'. He writes:

\#Tea-Towel-tanga! (My cousin, Wayne Ngata, recently told a group of Māori senior public servants that a sign of leadership is the person who helps to wash those 1000 cups and saucers. He calls this Tea-towel-tanga. In other words, leaders don't just talk, but they also roll their sleeves up and get their hands 'soapy'! Now the truth is, if you are a guest, then noone is going to invite you into the back of the kitchen. That's bad manners. But if it's a small meeting, and you've got some time, and you really want to connect with the people ... pick up a tea towel.).

Exercising good tea-towel-tanga is crucial to building and maintaining relationships that will enable long-term success in redevelopment projects. A particularly embarrassing experience I had in a recent project came at the end of an engagement process I was part of at a secondary school. A government official shouted across the room to the designers, in front of the remaining students and teachers, 'we're not paying you big money to tidy up, please leave the tidying up'. Tea-towel-tanga is a seemingly trivial but fundamental protocol in support of genuine relationship building.

Tibble also talks of the importance of small reciprocities: 'Bring biscuits! (Seriously ... sharing is caring. One of my work mates always takes biscuits now when we visit places. It's awesome the reaction she gets. But also, bring YOUR value to the meeting.)'. He adds, 'Always leave a koha! (Always try to leave people you are visiting in a better place than when you arrived.)'. Leaving people in a better place than when you arrived must surely sit at the heart of any housing or urban-development project. Having built strong relationships and good rapport, it would be hard to justify anything less than an engagement process that sits at the empowerment end of the IAP2 spectrum. Avoiding 'light on action' scenarios, as noted above in regard to the Tāmaki project, would surely call for refined and thoughtful participatory-design processes. In terms of what this might look like, David de la Peña et al suggest that, 'for participatory design to be truly democratic it cannot remain a standardized public process. ... It needs to move beyond 
conventional processes that are formulaic, closed, abstract, superficial, and monofunctional. Participatory design must become contextual, open, experiential, substantive, and holistic'. ${ }^{30}$

Given that there is extensive knowledge on how to design good cities (some might call this best practice or an evidence base), I argue that there is an educative or capacity-building role inherent in meaningful community engagement. My experience suggests that this is a two-way process, with learning happening on both sides of the engager/engaged divide, especially when the engager is not from that community. It is crucial that engagers provide tools in the form of design principles, evidence, and examples of best practice to communities. Such tools provide the community being engaged with something tangible to springboard off, allowing them to make educated decisions about the development outcomes they want and how these might be achieved. Nisha and Nelson argue for 'evidenceinformed decision making for participatory urban design'. ${ }^{31}$ They suggest that a successful engagement process must:

(1) Be willing to make clear and explicit statements of the values that underpin the regenerative design proposals, and most importantly spend more time in arriving at these values backed up by specific evidence.

(2) Unbolt the design process and hence the decision-making process to as much open participation as possible.

(3) Not limit this participation as a design review exercise but facilitate exploratory mechanisms to build up the evidence; and review and prioritise it to inform the values that then guides the spatial re-configuration of the urban area.

(4) Establish common denominators that communicate between rational and collaborative paradigms. ${ }^{32}$

30 David de la Peña et al (eds.), Design as Democracy: Techniques for Collective Creativity (Washington: Island Press, 2017), 1. This book offers many techniques that might be used to achieve this more desirable design process.

31 Nisha and Nelson, 'Making a Case for Evidence-informed Decision Making,' 336-348.

32 Nisha and Nelson, 'Making a Case for Evidence-informed Decision Making,' 340-341. 
Conversely, engagers may need help understanding how to interpret community knowledges and mātauranga. Both groups may have their own 'language', with 'designer speak' not necessarily being the same as that of the communities they are serving. Acknowledging these different languages and perspectives, collaboratively articulating shared principles, and establishing common and divergent goals is critical for creating shared understandings of what is possible and probable.

Engagement processes need to be brought to the community at times and places that suit them. In all of the projects I have been involved in, local and central government have dictated the terms, holding public meetings at pre-determined times and inviting community members to come along. While this was convenient for those doing the engagement, it was not always convenient for those being engaged, and further evaluation is required around who exactly attends these types of meetings and which parts of the community get side-lined by this type of practice. Meenakshi Sankar reinforces the limits of this practice, stating:

There is a growing recognition that public consultation as a tool for citizen engagement is limited in that the process is often driven by the policy agencies, and the timetable, format and issues for consultation are defined by the government agency. In such instances, the policy makers set the agenda and communities or voluntary groups are asked to air their views and opinions about the policy, but have little control over the process or the outcome. It is therefore not surprising that communities end up feeling powerless, frustrated and disenchanted with government processes. ${ }^{33}$

A further source of powerlessness is the oft-perceived disconnect between community contributions to engagement and final design proposals. This is rooted in the separation of engagement and design roles, which leads to an inability to iteratively develop design proposals alongside the community. Engagement and design consultants need to be employed

33 Meenakshi Sankar, 'Bridging the Gap Between Policy, Research and Practice: Experiences from a Community Economic Development Action Research Project in New Zealand,' Social Policy Journal of New Zealand no. 26 (2005): 54. 
to work intimately alongside one another to ensure that both processes are inextricably linked. If one is hived off from the other, the resultant design proposal may not be sophisticated enough to respond to the nuances that may have been missed if engagement consultants are not aware of the spatial implications of engagement feedback. The marriage between engagement and design needs to continue throughout, ensuring that clear thought trajectories and articulated design rationales will result in a design outcome that communities can recognise as a response to their input.

Relatedly, rebuffing traditional approaches requires new ways to foster participation. As de la Peña et al state of participatory design:

we need to reform and to re-form. Reforming means tackling abuses, rethinking old methods, and seeking more just outcomes. Re-forming means forming again, and again, and again. It is a continuous process of shaping and reshaping civic landscapes so they can be informed and inhabited by deep democracy. To accomplish these ends, participatory design must not only have good intentions, it must also refine its democratic techniques. Innovative techniques can strengthen meaningful relationships between communities and designers, help revitalize participatory design as it breaks barriers to collective creativity, and open doors to possibilities that are yet unimagined. ${ }^{34}$

Imagining the unimagined necessarily draws on the mātauranga of communities. This mātauranga is place-based, lived experience that cannot, by definition, be found elsewhere; it must be acknowledged. To return to a point I made earlier, I have never seen a community acknowledged on an architectural award as one of the partners in the project.

\section{Conclusion}

Local and central government community-engagement practice in Aotearoa New Zealand is variable, consistently falling short of a standard one might 
expect from agents of a democratic agenda. The commonly used IAP2 spectrum, while useful for illuminating levels of engagement, seems to be utilised without any further consideration of what might be best practice for encouraging engagements that empower communities. IAP2 practice also lacks Aotearoa New Zealand-specific utility. Tibble's ideas provide a useful corrective here; he offers nuanced insights gleaned from engaging with Māori communities across the country. Despite focusing on Māori engagement, his advice is also useful for engaging with other communities in this country.

A successful engagement process empowers communities by acknowledging their mātauranga, and by taking the time to build strong relationships that can form the base of all future engagement. Specifically, there is a range of things agencies and those doing the engaging need to do. These include: engaging with communities early; allowing them to be part of priority setting in terms of what kind of engagement should be done and at what stage; and ensuring that governance boards and steering groups include community voices from early in the process. In doing so, they should not be afraid to bring critical voices into the centre of the process - so long as other parts of the community, particularly 'hard to reach communities', are also represented and good faciliation enables all to be heard.

Much more time should be invested upfront in developing relationships to ensure that those who are not so vocal get a chance to engage. This will be aided by a focus on building personal rapport with cups of tea and hongi, and learning appropriate tikanga in order to engage in respectful and mana-enhancing ways. Those engaging should be curious: learn appropriate tikanga and seek to understand the community; listen and watch before speaking-understand who is in the room, what their concerns might be, and how they think things should change. Be there until the end, and get in the kitchen and help with the clean-up to build relationships and dismantle power imbalances. Think about small reciprocities such as bringing biscuits and leaving a koha, and understand that the process is truly reciprocalas the community have a wealth of knowledge and experience to bring 
to the redevelopment equation. Those doing the engagement and design also benefit from such processes, and need to recognise that international knowlege and precedent is not necessarily better than local knowledge. Ensure that designers and those doing the engagement (if different people) work together intimately to enable the uninterupted flow of community mātauranga through to the final design outcome. Relatedly, ensure community engagement is not limited to a design review exercise. Consider methods that encourage two-way conversations and provide communities with the tools with which to critique the process, and add their mātauranga to it. Avoid traditional design approaches that treat the redevelopment as a design product; rather, consider it a design process. Throughout all stages of engagement, keep democratic process central to planning and redevelopment.

Further work needs to be done to encourage the systematic use of best practice when it comes to engaging communities in housing and urbandevelopment projects. Communities have so much to offer such processes, and they are the ones who will feel the brunt or enjoy the benefitsdepending on the outcome-of these projects. Our towns and cities should provide for everyone, and so they should be created by everyone. We cannot leave this important job in the hands of a few government officials and built-environment professionals. This takes time and the adoption of a new value-set that privileges relationships and reciprocity. Reciprocity needs to happen in both the small details of a project and at a larger scale. Valuing local mātauranga, creating space for community members in decisionmaking bodies, and including an educative element in the engagement process are all critical to building neighbourhoods that will continue to be successful and liveable places, enjoyed by communities well into the future. 


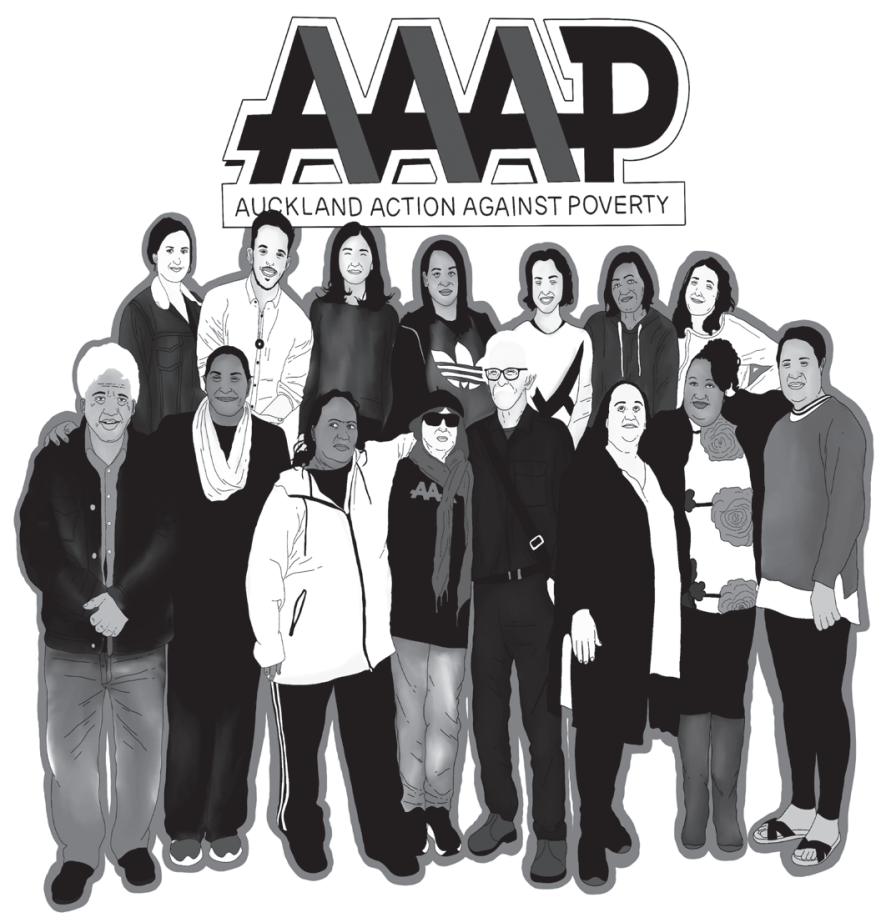

SUPPORT AUCKLAND ACTION AGAINST POVERTY TO FIGHT FOR

\section{'LIVEABLE INCOMES FOR ALL'}

WE ARE AN ADVOCACY \& ACTION GROUP FIGHTING FOR A SOCIAL SECURITY SYSTEM WHERE EVERYONE CAN LIVE WITH DIGNITY. WE WORK WITH LOW-INCOME WORKERS AND BENEFICIARIES TO ENSURE PEOPLE GET THEIR FULL ENTITLEMENTS FROM WORK \& INCOME AND TO COLLECTIVELY FIGHT FOR A DIFFERENT SYSTEM! ALL PEOPLE, WHETHER IN PAID OR UNPAID MAHI, AND REGARDLESS OF THEIR RELATIONSHIP STATUS, SHOULD HAVE A LIVEABLE INCOME.

FOLLOW US ON FACEBOOK: FACEBOOK.COM/AAAPNZ MAKE A REGULAR DONATION: 38-9011-0832874-00 